This item was submitted to Loughborough's Research Repository by the author.

Items in Figshare are protected by copyright, with all rights reserved, unless otherwise indicated.

\title{
Analytical study of the heat loss attenuation by clothing on thermal manikins under radiative heat loads
}

PLEASE CITE THE PUBLISHED VERSION

http://www.ciop.pl/22441.html

\section{PUBLISHER}

(c) Central Institute for Labour Protection - National Research Institute

VERSION

VoR (Version of Record)

\section{LICENCE}

CC BY-NC-ND 4.0

\section{REPOSITORY RECORD}

Hartog, Emiel A. den, and George Havenith. 2019. "Analytical Study of the Heat Loss Attenuation by Clothing on Thermal Manikins Under Radiative Heat Loads". figshare. https://hdl.handle.net/2134/8236. 
This item was submitted to Loughborough's Institutional Repository (https://dspace.lboro.ac.uk/) by the author and is made available under the following Creative Commons Licence conditions.

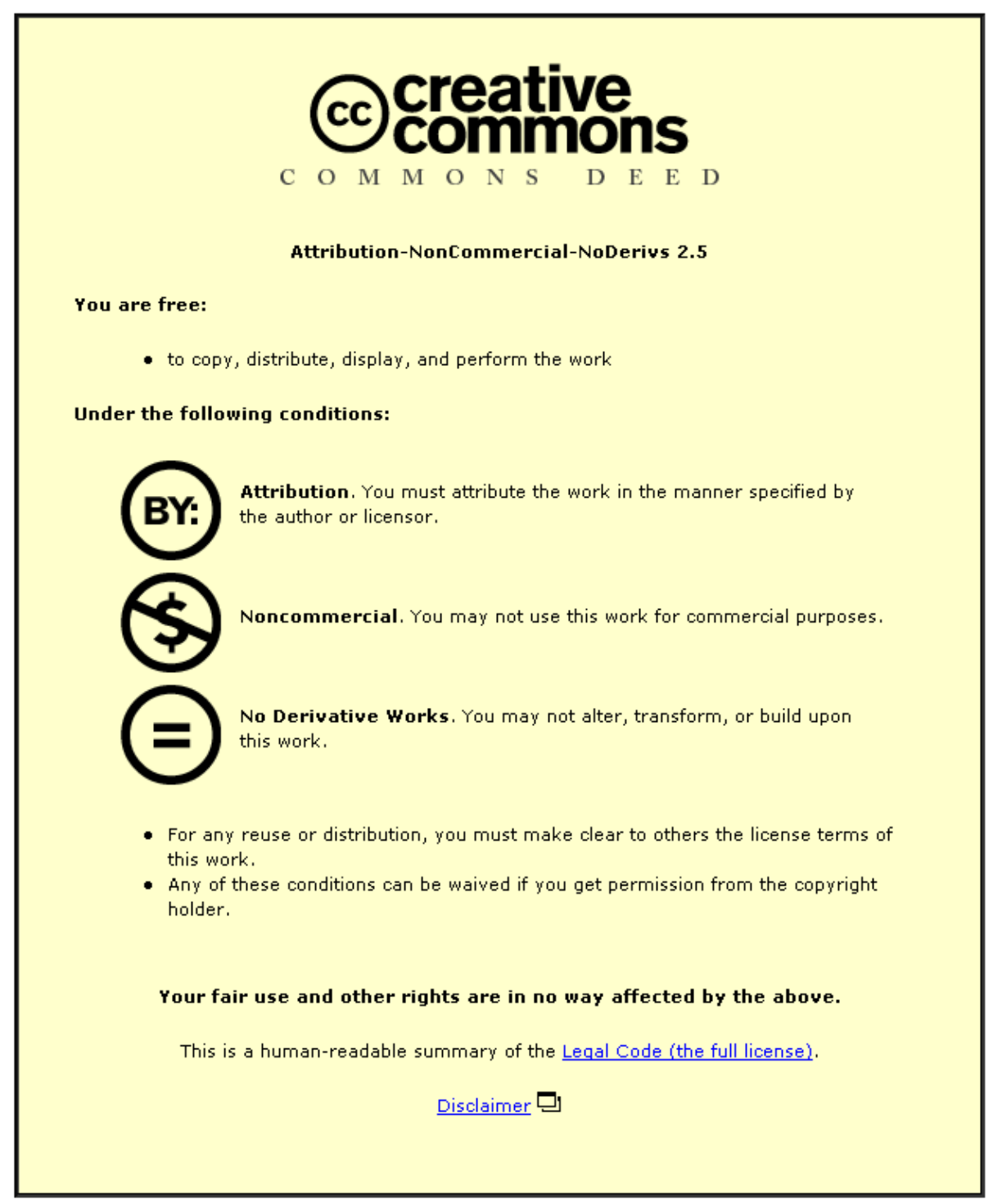

For the full text of this licence, please go to: http://creativecommons.org/licenses/by-nc-nd/2.5/ 


\title{
Analytical Study of the Heat Loss Attenuation by Clothing on Thermal Manikins Under Radiative Heat Loads
}

\author{
Emiel A. Den Hartog \\ Business Unit CBRN Protection, TNO Defence, Security and Safety, Rijswijk, The Netherlands
}

\section{George Havenith}

\section{Department of Human Sciences, Loughborough University, Loughborough, UK}

\begin{abstract}
For wearers of protective clothing in radiation environments there are no quantitative guidelines available for the effect of a radiative heat load on heat exchange. Under the European Union funded project ThermProtect an analytical effort was defined to address the issue of radiative heat load while wearing protective clothing. As within the ThermProtect project much information has become available from thermal manikin experiments in thermal radiation environments, these sets of experimental data are used to verify the analytical approach. The analytical approach provided a good prediction of the heat loss in the manikin experiments, 95\% of the variance was explained by the model. The model has not yet been validated at high radiative heat loads and neglects some physical properties of the radiation emissivity. Still, the analytical approach provides a pragmatic approach and may be useful for practical implementation in protective clothing standards for moderate thermal radiation environments.
\end{abstract}

protective clothing heat stress heat budget models thermal manikin thermal radiation infrared radiation solar radiation

\section{INTRODUCTION}

In the area of heat exchange through clothing a lot of work has been done on predicting heat loss from humans in different environments ranging from Kerslake [1] to more recent publications $[2,3,4,5,6]$. These models and predictions are used in standards like Standard No. ISO 7933:2004 [7] to provide guidelines for safe exposure times in warm and hot conditions. Most of these prediction standards and models exclude wearers of specialized protective clothing from the application range, due to the limited knowledge on heat transfer processes within such clothing. Especially for thermal radiation protective clothing there are no quantitative guidelines available for the effect of a radiative heat load on heat exchange. Within the European Union funded project ThermProtect an effort was defined to address the issue of radiative heat load while protective clothing is worn. Several experiments were performed, aimed at understanding the interaction of radiation with protective clothing. Subsequently, a modelling effort was defined to

This work was funded as a European Union GROWTH programme project ThermProtect, Assessment of Thermal Properties of Protective Clothing and Their Use, contract G6RD-CT-2002-00846. The authors thank the partners in this project for their collaboration: P. Bröde (IfADo), K. Kuklane (Department of Design Sciences, EAT, Lund University, Sweden), V. Candas (Centre d'Etudes de Physiologie Appliquée, France), B. Griefahn (IfADo), I. Holmér (Department of Design Sciences, EAT, Lund University, Sweden), H. Meinander (SmartWearLab, Tampere University of Technology, Finland), W. Nocker (W.L. Gore \& Associates GmbH, Germany) and M. Richards (Humanikin GmbH, Switzerland).

Correspondence and requests for offprints should be sent to Emiel A. Den Hartog, TNO Defense, Security and Safety, P.O. Box 45, 2280 AA, Rijswijk, The Netherlands. E-mail: <Emiel.denhartog@tno.nl>. 
analyse the data and come up with guidelines on the translation of the experimental data to the protective clothing standards. For this purpose a series of modelling efforts was performed within the ThermProtect project, from empirical data modelling to finite element modelling on the heat transfer in the flat plate measurements. In this paper the usability of an analytical approach is studied and guidelines are given on how such an approach might be used in the standards on protective clothing.

Studying heat exchanges in protective clothing while it is worn by a human subject is highly complex $[3,4,5,8]$, due to the interactions of the different heat loss pathways [9] and the difficulty of measuring these pathways individually. An alternative method is to measure these heat transfers on thermal manikins, which provide a direct measurement of heat loss in different body areas rather than in one through indirect calorimetry as needed in humans. This approach was used for the present project.

In the ThermProtect project an extensive series of experiments was run to study the effect of radiation on heat exchange through the clothing [10]. The experimental parameters varied in radiation intensities, clothing insulation, air temperature, wind speed and reflectivity of the clothing. Also, two radiative spectra were used, in the visible solar range (VIS) and in the far infrared range (FIR), to account for differences caused by solar radiation and radiative heat from hot surfaces. Starting from these properties and aiming at taking the clothing properties into account, an analysis was set up with which the decrease in manikin heat loss due to radiation was predicted and consequently compared to the experimental data.

This paper only describes the analytical effort; more extensive information on the materials, materials measurements, manikin measurements, etc., can be found in other ThermProtect publications (e.g., Havenith, Holmér, Meinander, et al. [10], Havenith and Wang [11] and Bröde, Kuklane, den Hartog, et al. [12]).

In this analytical effort two steps will be presented. The first working towards a correction of the climate parameters for clothing radiative properties, so that standard calculations can be used; the other one towards include the attenuation effects of clothing insulation.

\section{ANALYTICAL APPROACH}

\subsection{Starting Points and Limitations}

The work presented in this report was intended as an analytical study to describe the physical processes of radiative heat exchange through protective clothing. It was not intended to be a full indepth analysis of the physics processes, but rather an effort to use a simplified approach to study the different parameters involved in practical working environments. Therefore, the use and the validity of the model presented here will be limited to the range of temperatures and radiation that have been used in the manikin experiments.

The model presented here is based on the steady-state equations and the linearization of the radiative heat loss from humans in clothing. Also, mean values for the emissivity are used for parts of the radiation spectrum, whereas theoretically the emissivity continuously varies with the wavelength.

When studying radiation, one of the problems is that most manikins have no provision for cooling the skin, and thus temperature may increase above the setpoint, rendering the data unusable. In the experiments from which the data were used here, this was counteracted by promoting other heat loss pathways (lower temperature, more wind), but this limited the maximal radiant heat loads.

\subsection{Experimental Conditions Used}

Within ThermProtect a range of experimental conditions was identified to study the effect of radiation on heat exchange through clothing. In this paper the rationale behind the choices of the conditions will not be discussed as this can be found elsewhere (see, e.g., Havenith et al. [10]; Bröde, Candas, Kuklane, et al. [13]; Kuklane, Gao, Holmér, et al. [14]). The results of the experiments that were performed within 
ThermProtect serve as the database against which the model results were validated.

The experiments were performed with thermal manikins in climatic chambers at IfADo (Germany) with the TORE manikin from Lund University (Sweden), Loughborough University (UK, the Newton manikin) and CNRS (France, the Heatman). All manikins were placed in the climatic chamber at relatively low air temperatures $\left(5-12^{\circ} \mathrm{C}\right)$ to ensure sufficient heat loss during the radiation experiments (cf. Table 2). Standard wind speed was $0.5 \mathrm{~m} / \mathrm{s}$, but some experiments were performed at higher wind speeds of 1,2 and $5 \mathrm{~m} / \mathrm{s}$.

\subsubsection{Environmental conditions}

In the ThermProtect project two major sources were identified as typical heat sources in human work. The first is the sun, whose spectrum contains the visible spectrum and the near infrared (IR) spectrum. The full spectral range of the solar radiation is $200-2000 \mathrm{~nm}$; still, this range will be named the VIS spectral range from here on.

Another important spectrum is the thermal or FIR range. The wavelengths typically range from $\sim 1$ to $10 \mu \mathrm{m}$ and the sources of this radiation are hot surfaces, furnaces and fires.

As the manikins can only be used for measurements when they give off heat to the environment, the levels of mean radiant temperature that could be used were limited. By varying wind speed, a range of different conditions could still be studied (Table 2).

Radiation was induced with different methods:

- an IR radiation panel was used at the front of the manikin $[10,13]$;

- two solar lamps were used to simulate solar radiation $[10,12,15]$;

- in one limited data set experiments were performed with increased wall and ceiling temperatures to induce long-wave IR radiation.

Temperatures and radiation levels were set to the desired values of the mean radiant temperature as derived from the black globe temperature in the range from 5 to $50^{\circ} \mathrm{C}$ (Table 2).

\subsubsection{Clothing materials}

In the first tasks of ThermProtect a number of materials were identified to be used in manikin and human experiments. The materials are listed in Table 1. The focus was on Nomex ${ }^{\circledR}$ materials as these are very common in applications where protection against high radiative heat loads is required. To account for the effects of visual aspects different colors were used on Nomex ${ }^{\circledR}$ and also materials with an added aluminized reflective layer were tested. Additionally a series of experiments were performed on black and white cotton materials. To account for the effects of different underwear insulations extra measurements were performed with varying numbers of layers of underwear. Spectral data on reflection, transmission and absorption were determined according to Standard No. EN 410:1998 [16] for the solar spectrum range. A similar internal test method was used for the data in the FIR range (5 and $10 \mu \mathrm{m})$.

It is crucial in this modelling approach to have the data on emissivity for the used garments in the radiative fields. An extensive description of the materials and the suits can be found in the ThermProtect reports on materials and manikin measurements. Table 1 presents the data on radiation emissivity, transmission and reflectivity of the materials that were used in the manikin experiments. In the VIS spectrum the emissivity values for black and orange Nomex ${ }^{\circledR}$ turned out to be approximately the same as for the black cotton material. Only white cotton had higher reflectivity in the visible light, but that decreased quickly in the (near) IR region. The actual values for emissivity that were used in the analysis were based on the weighted average of the emissivity values at the different wavelengths by the distribution of the intensity of the solar simulator (Thorn lamp [10, 15]). With this method the wavelengths that were most prominent in the spectrum of the source were represented accordingly. The value for black Nomex® that was thus obtained for the analysis was $\varepsilon=.68$, slightly higher than for orange Nomex $®$, because of the slightly higher values of emissivity in the visible range. For the FIR spectrum the materials also show small variation in emissivity 


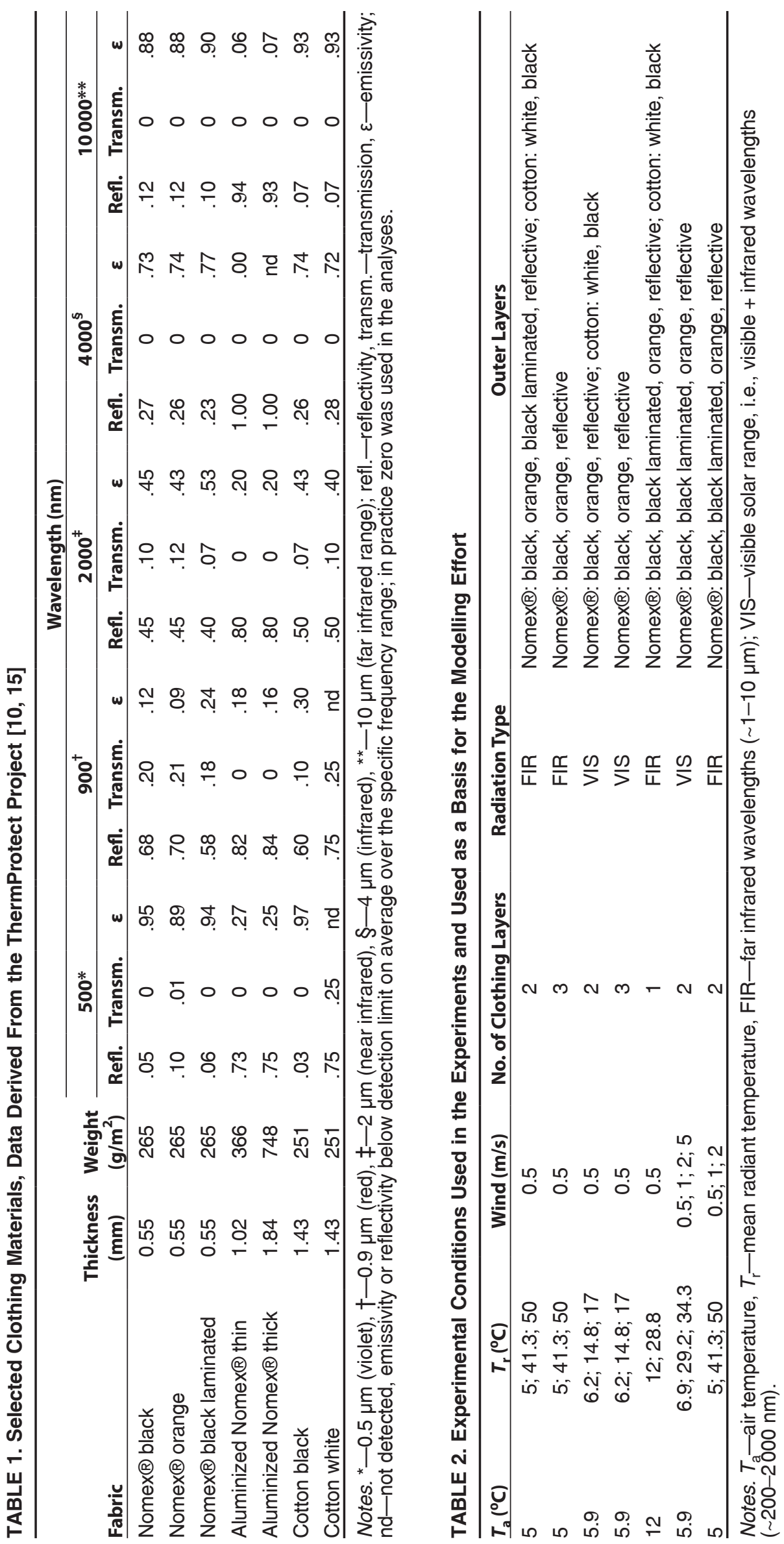


values. A value of .88 was obtained here for the Nomex ${ }^{\circledR}$ materials, .93 for the cottons and .07 for the reflective material. These values represent approximations, but they give a weighed average over the spectra of the lamps.

\subsection{Analytical Step 1: Effect of Emissivity on the Radiative Field}

For the modelling effort we need the following list of symbols (and units)

$T_{\mathrm{a}} \quad$ air temperature $\left({ }^{\circ} \mathrm{C}\right)$

$T_{\mathrm{r}}$ mean radiant temperature as calculated from $T_{\mathrm{g}}$ according to Standard No. ISO 7726:2001 [17] $\left({ }^{\circ} \mathrm{C}\right)$

$T_{\mathrm{g}} \quad$ black bulb temperature as measured with the device as usual $\left({ }^{\circ} \mathrm{C}\right)$

$\varepsilon \quad$ the emissivity (absoptivity) of a material

$I_{\mathrm{r}}$ radiation intensity, here represented as incident radiation flux to an object, with reference to the surrounding air temperature $\left(\mathrm{W} / \mathrm{m}^{2}\right)$

$v_{\text {wind }}$ wind speed $(\mathrm{m} / \mathrm{s})$

$I_{\mathrm{cl}} \quad$ clothing insulation $\left(\mathrm{m}^{2} \mathrm{~K} / \mathrm{W}\right)$

$I_{\text {tot }}$ total insulation to manikin heat loss $\left(\mathrm{m}^{2} \mathrm{~K} / \mathrm{W}\right)$

$I_{\mathrm{a}} \quad$ insulation of surrounding air $\left(\mathrm{m}^{2} \mathrm{~K} / \mathrm{W}\right)$

$h_{\mathrm{cl}}$ clothing heat transfer coefficient $\left(1 / I_{\mathrm{cl}}\right)$ $\left(\mathrm{W} / \mathrm{m}^{2} \mathrm{~K}\right)$

$h_{\text {tot }}$ total heat transfer coefficient $\left(1 / I_{\text {tot }}\right)\left(\mathrm{W} / \mathrm{m}^{2} \mathrm{~K}\right)$

$h_{\mathrm{a}}$ heat transfer coefficient of surrounding air $\left(\mathrm{W} / \mathrm{m}^{2} \mathrm{~K}\right)$

$h_{\mathrm{c}}$ convective heat transfer coefficient of air layer $\left(\mathrm{W} / \mathrm{m}^{2} \mathrm{~K}\right)$

$h_{\mathrm{r}}$ radiative heat transfer coefficient of air layer $\left(\mathrm{W} / \mathrm{m}^{2} \mathrm{~K}\right)$

$f_{\mathrm{cl}} \quad$ clothing area increase factor

$T_{\mathrm{cl}} \quad$ clothing surface temperature $\left({ }^{\circ} \mathrm{C}\right)$

$T_{\text {sk }} \quad$ skin temperature, $34{ }^{\circ} \mathrm{C}$ for most manikin measurements $\left({ }^{\circ} \mathrm{C}\right)$

$M$ metabolism, here taken as the manikin heat loss $\left(\mathrm{W} / \mathrm{m}^{2}\right)$

$M_{\text {rad }}$ manikin heat loss under radiation conditions, with a radiative field from a radiation (hot) source $\left(\mathrm{W} / \mathrm{m}^{2}\right)$

$M_{\mathrm{o}}$ manikin heat loss under non-additional radiation conditions, i.e., only the radiative heat exchange between the manikin/ clothing and its environment is present and no extra source of radiation $\left(\mathrm{W} / \mathrm{m}^{2}\right)$

Later a few extra symbols are introduced:

$A R T$ apparent (theoretical) mean radiant temperature with corresponding black globe temperature $\left(T_{\mathrm{g} \_a p p}\right)$ that gives the same heat exchange as a non-black globe with emissivity $\varepsilon$ in a radiative environment with mean radiant temperature $\left(T_{\mathrm{r}}\right)\left({ }^{\circ} \mathrm{C}\right)$

$I_{\mathrm{r} \_a p p}$ radiation intensity that is absorbed by the bulb (that is not "black") $\left(\mathrm{W} / \mathrm{m}^{2}\right)$

In most standards dealing with heat and cold stress, radiation is described in terms of globe temperature (WBGT) or as mean radiant temperature. For the experimental conditions, this same approach was used. The heat exchange data observed have so far been presented as the change in manikin heat loss (i.e., the effect of the radiation) versus the $T_{\mathrm{r}}-T_{\mathrm{a}}$ difference $[13,14$, $15,18]$. The term $h_{\mathrm{r}} \cdot\left(T_{\mathrm{r}}-T_{\mathrm{a}}\right)$ is often used in the analysis of radiative environments for clothing as a linearized simplification of $T_{\mathrm{r}}^{4}-T_{\mathrm{a}}^{4}$, which theoretically describes the radiative environment. At low to moderate levels of radiation this is considered a valid approach $[2,8]$. In this linearized simplification the parameter $h_{\mathrm{r}}$ equals $\varepsilon \sigma \check{\mathrm{T}}^{3}$. In this equation $\varepsilon$ represents the emissivity of the clothing surface, $\sigma$ represents the StefanBoltzmann constant $\left(\sigma=5.67 \quad 10^{-8} \mathrm{~J} / \mathrm{sm}^{2} \mathrm{~K}^{4}\right)$ and $\check{\mathrm{T}}^{3}$ is the mean temperature between the radiant temperature $\left(T_{\mathrm{r}}\right)$ and the clothing surface temperature $\left(T_{\mathrm{cl}}\right)$. In this analysis the value of $\varepsilon$ should be derived from the value that is related to the emitted radiation at temperature $T_{\mathrm{cl}}$.

Considering the measurement of radiation with the black globe, it is important to realize that the black globe does not represent the environment that a wearer of, e.g., a reflective aluminum suit experiences. The black globe is designed to absorb (and emit) all the radiation of the environment either from heat sources or from the walls. However, as was measured within ThermProtect (cf. Table 1) the reflective material reflected $\sim 90 \%$ of the radiation, especially in the FIR range of the spectrum such as used in some experiments [13]. Would the black globe be covered with that material, 
then it would read a different globe temperature $T_{\text {globe }}$. More importantly, textile materials may have a significant reflection in the VIS spectrum; however, a very low reflectance in the far IR range. This was found in the materials used in this study (cf. Table 1), but also in a previous study [8]. It may be a more general property of textile materials; however, we do not have

(a)
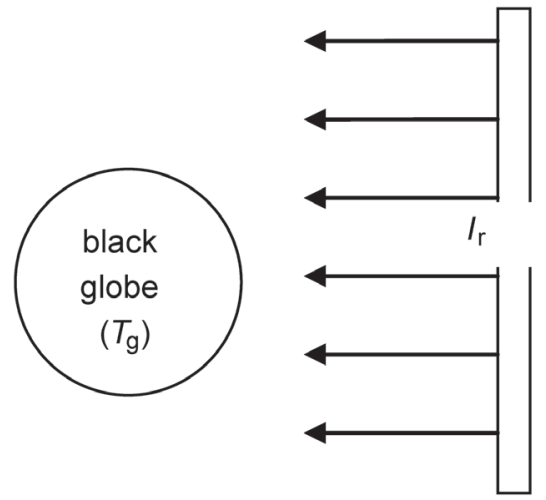

radiation

field $\left(I_{r}\right)$ the data available to sustain that. In theory, equations must be used that account for all emissivity values, from all parts of the radiation spectrum concerned. In practice, these values are continuously changing through the spectrum and are not readily available for users. As this might be difficult to use in practice an analytical approach was looked for, one that might allow (b)

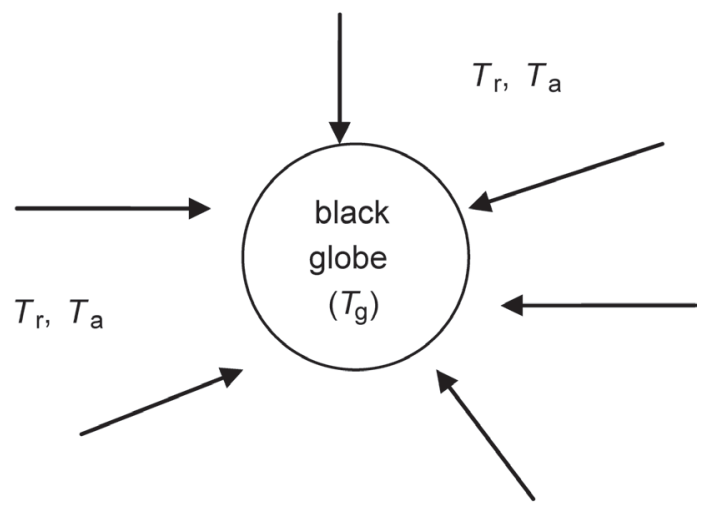

homogenous

radiation field $(/ \mathrm{r})$

Figure 1a. Black globe $(\varepsilon=1)$ in non-uniform radiative field. Notes. $\varepsilon-e m i s s i v i t y$ (absoptivity) of a material. Figure 1b. Same black globe temperature $T_{\mathrm{g}}$ as in Figure 1a, in a homogenous radiative field with corresponding $T_{\mathrm{r}}$. Notes. $T_{\mathrm{g}}$ —black bulb temperature as measured with the device; $T_{\mathrm{r}}$-mean radiant temperature.

(a)

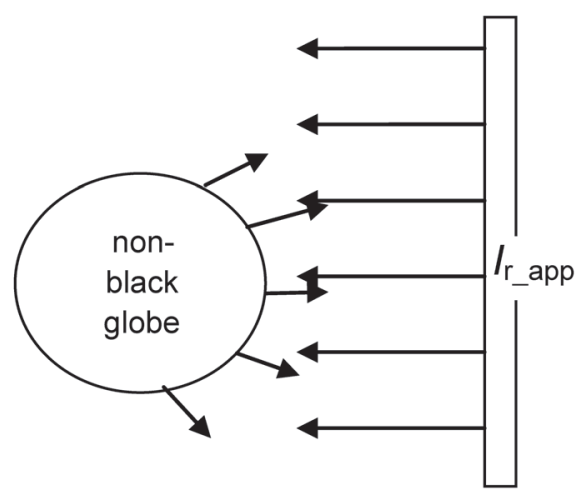

apparent radiation field to a non-black globe

$\left(I_{r_{-} \text {app }}<I_{r}\right)$ as part of $I_{r}$ is reflected (b)

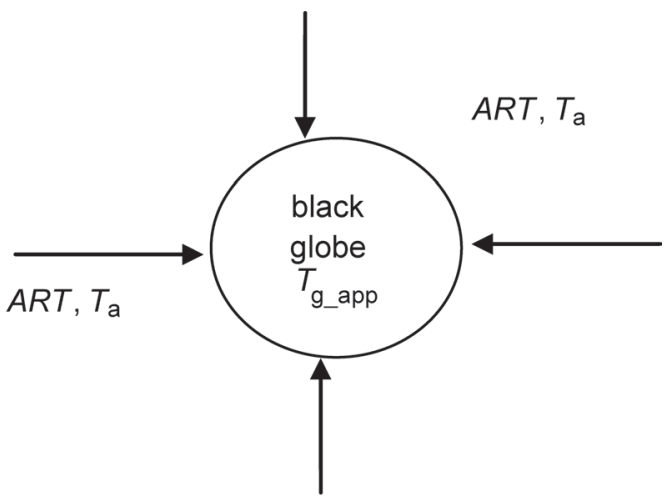

apparent homogenous radiation field $I_{r_{-} \text {app }}$

Figure 2a. Non-black globe $(\varepsilon<1)$ in same radiative field as Figure 1a. Notes. $\varepsilon$-emissivity (absoptivity) of a material.

Figure $2 \mathrm{~b}$. Non-black globe temperature from Figure $2 \mathrm{a}$ is converted into an apparent black globe temperature $T_{g_{\_} \text {app }}$, with corresponding homogenous radiative field $I_{r_{-} \text {app. }}$. This apparent black globe temperature has again a corresponding (apparent) mean radiant temperature ART. Notes. $I_{r_{-} \text {app }}-$ radiation intensity that is absorbed by the bulb (that is not "black"). 
the use of one emissivity value, for the FIR range, and still account for a different reflectivity in other spectral ranges. The rationale for selecting the emissivity value in the FIR range was that the emitted radiation from the clothing is in that range as the clothing surface is usually in moderate temperatures. Clothing temperatures may roughly be expected to range from 0 to $100{ }^{\circ} \mathrm{C}$. The radiation theory states that any object emits radiation, and that the wavelength depends on the temperature of the surface. The theory predicts the emission of radiation from the clothing surface $\left(0-100{ }^{\circ} \mathrm{C}\right)$ to be in the range of 15-20 $\mu \mathrm{m}$, i.e., in the FIR range.

The aim was to find an acceptable compromise between the current practice and the much more complex, formal physics approach, which would explain the variations that were found from manikin experiments [10, 13, 14]. This line of thinking is further explained in Figures 1-2.

Following through with this thought and working through the equations, the following derivation was obtained. For the normal black globe we have

$$
I_{\mathrm{r}}=h_{\mathrm{r}}\left(T_{\mathrm{r}}-T_{\mathrm{g}}\right)
$$

and for balance

$$
h_{\mathrm{r}}\left(T_{\mathrm{r}}-T_{\mathrm{g}}\right)=h_{\mathrm{c}}\left(T_{\mathrm{g}}-T_{\mathrm{a}}\right) .
$$

Now, consider a bulb that is not black (but grey) in the spectrum of the radiative field. A part of the radiation will be reflected by the grey globe (Figures 2a, 2b). One would not measure a value of $T_{\mathrm{g}}$ with that globe but rather a value we will call $T_{\mathrm{g} \_a p p}$. This situation may be approached by stating that the grey globe will absorb an amount of radiation equal to $\varepsilon I_{\mathrm{r}}$, the rest is reflected. Then, the grey globe will indicate the same temperature as a hypothetical black globe in a radiative field that equals $\varepsilon I_{\mathrm{r}}$. The grey globe temperature $\left(T_{\mathrm{g} \_ \text {app }}\right)$ value will be lower than the value for the black globe $\left(T_{\mathrm{g}}\right)$ and the attenuation factor will be related to $\varepsilon$.

Using this concept we obtain, for the black globe

$$
I_{\mathrm{r}}=h_{\mathrm{r}}\left(T_{\mathrm{r}}-T_{\mathrm{g}}\right)
$$

and for the grey globe

$$
I_{\mathrm{r} \_ \text {app }}=\varepsilon I_{\mathrm{r}}=\varepsilon h_{\mathrm{r}}\left(T_{\mathrm{r}}-T_{\mathrm{g} \_ \text {app }}\right) .
$$

Both together yield

$$
T_{\mathrm{g} \_ \text {app }}=(1 / \varepsilon) \cdot T_{\mathrm{g}}+((\varepsilon-1) / \varepsilon) \cdot T_{\mathrm{r}} .
$$

This value of $T_{\mathrm{g} \_a p p}$ instead of $T_{\mathrm{g}}$ could be used to correct for the reflective properties of materials. It would be preferable to use a property such as $T_{\mathrm{r}}$, which represents the radiative environment and does not incorporate factors such as the wind speed which influence $T_{\mathrm{g}}$.

We start with a hypothetical translation of the situation as presented in Equation 1, with a radiative field $I_{\mathrm{r}}$ and with a grey globe and the value of $T_{\mathrm{g} \text { app }}$ that is obtained by the globe. Next we use a theoretical concept of a real black globe that would yield the same value $\left(T_{\mathrm{g} \_ \text {app }}\right)$ as the grey globe. The radiative heat gain of this globe would be the same as of the grey globe as the balancing convective heat loss is the same because the temperature difference with the air $\left(T_{\mathrm{g} \_a p p}-T_{\mathrm{a}}\right)$ is the same. This yields

$$
I_{\mathrm{r} \_a p p}=\varepsilon h_{\mathrm{r}}\left(T_{\mathrm{r}}-T_{\mathrm{g} \_ \text {app }}\right) \quad \text { (grey globe) }
$$

and

$$
I_{\mathrm{r}_{\text {app }}}=h_{\mathrm{r}}\left(\mathrm{ART}-T_{\mathrm{g} \_ \text {app }}\right)
$$

(hypothetical new black globe with same $T_{\text {g_app }}$ ) with corresponding convective heat loss for both of them

$$
h_{\mathrm{r}}\left(A R T-T_{\mathrm{g} \_ \text {app }}\right)=h_{\mathrm{c}}\left(T_{\mathrm{g} \_ \text {app }}-T_{\mathrm{a}}\right) .
$$

Otherwise stated, $A R T$ is a hypothetical mean radiant temperature that would lead to a real black globe temperature $T_{\mathrm{g} \_ \text {app }}$ in a homogenous radiation environment (with intensity $I_{\mathrm{r}_{\_} \text {app }}$ and the same $T_{\mathrm{a}}$ ).

And thus from Equation 2

$$
T_{\mathrm{g} \_ \text {app }}=\left(h_{\mathrm{c}} T_{\mathrm{a}}+h_{\mathrm{r}} A R T\right) /\left(h_{\mathrm{r}}+h_{\mathrm{c}}\right),
$$

which is still similar to the usual equation for $T_{\mathrm{g}}$. If we start to fill in $I_{\mathrm{r} \_a p p}=\varepsilon I_{\mathrm{r}}$, we obtain

$$
I_{\mathrm{r} \_ \text {app }}=\varepsilon I_{\mathrm{r}}=h_{\mathrm{r}}\left(T_{\mathrm{g} \_ \text {app }}-A R T\right),
$$

together with

$$
\varepsilon I_{\mathrm{r}}=\varepsilon h_{\mathrm{r}}\left(T_{\mathrm{g} \_a p p}-T_{\mathrm{r}}\right) .
$$

If Equations 4-5 are combined, $A R T$ can be expressed as a function of $T_{\mathrm{g} \_ \text {app }}$ and $T_{\mathrm{r}}$

$$
A R T=\varepsilon T_{\mathrm{r}}+(1-\varepsilon) T_{\mathrm{g} \_ \text {app }} .
$$

Filling Equation 6 into Equation 3 we obtain 


$$
A R T=\varepsilon T_{\mathrm{r}}+(1-\varepsilon)\left(h_{\mathrm{c}} T_{\mathrm{a}}+h_{\mathrm{r}} A R T\right) /\left(h_{\mathrm{r}}+h_{\mathrm{c}}\right),
$$

which can be rearranged to

$$
\begin{aligned}
& A R T\left(\left(h_{\mathrm{r}}+h_{\mathrm{c}}\right)-(1-\varepsilon) h_{\mathrm{r}}\right) \\
= & \varepsilon\left(h_{\mathrm{r}}+h_{\mathrm{c}}\right) T_{\mathrm{r}}+(1-\varepsilon) h_{\mathrm{c}} T_{\mathrm{a}},
\end{aligned}
$$

which is further rearranged to

$$
A R T=\frac{\varepsilon\left(h_{\mathrm{r}}+h_{\mathrm{c}}\right)}{\left(h_{\mathrm{c}}+\varepsilon h_{\mathrm{r}}\right)} T_{\mathrm{r}}+\frac{h_{\mathrm{c}}(1-\varepsilon)}{\left(h_{\mathrm{c}}+\varepsilon h_{\mathrm{r}}\right)} T_{\mathrm{a}} .
$$

Carefully reworking Equation 7 leads to

$$
A R T=\chi T_{\mathrm{r}}+(1-\chi) T_{\mathrm{a}},
$$

in which $\chi$ is

$$
\chi=\varepsilon\left(h_{\mathrm{r}}+h_{\mathrm{c}}\right) /\left(h_{\mathrm{c}}+\varepsilon h_{\mathrm{r}}\right) .
$$

From this, we can redefine the used values of $T_{\mathrm{r}}-T_{\mathrm{a}}$ to the corrected values of $A R T-T_{\mathrm{a}}$ as

$$
A R T-T_{\mathrm{a}}=\chi\left(T_{\mathrm{r}}-T_{\mathrm{a}}\right),
$$

in which $\left(T_{\mathrm{r}}-T_{\mathrm{a}}\right)$ is a measure that is often used to identify the intensity of a radiative environment.

To explore these findings, the relationship between $A R T$ and extreme values of $\varepsilon$ can be analysed:

- $\varepsilon=0$ : is a $100 \%$ "ideal" reflective globe, i.e., no radiation at all is absorbed, $\chi=0$, leading to
$A R T=T_{\mathrm{a}}$. The radiative component becomes zero in all equations.

- $\varepsilon=1$ : represents the case of the black bulb (globe) again, $\chi=1$ and $A R T=T_{\mathrm{r}}$ is obtained. Figure 3 shows the relation between $\varepsilon, \chi$ and $h_{\mathrm{c}}$ (Equation 9). The values for $h_{\mathrm{c}}$ were used as input to the model. From literature estimates to compute the corresponding wind speed to values of $h_{\mathrm{c}}$ can be found: $h_{\mathrm{c}}=8.3 \cdot \sqrt{ } v_{\text {wind }}$ $[1,8]$.

The $\chi$ factor depends strongly on $h_{\mathrm{c}}$ and $h_{\mathrm{r}}$, and though they can be estimated [2, 7] and maybe known during experiments $[10,12]$ it may be difficult to use this concept in practice. The parameter $h_{\mathrm{c}}$ represents the convective heat transfer coefficient from the skin to the air and is determined by the air flow around the body. The parameter $h_{\mathrm{r}}$ represents the radiative heat transfer coefficient that is used in the linearized radiative heat exchange model (cf., e.g., Malchaire, Piette, Kampmann, et al. [2], Standard No. ISO 7933:2004 [7]). It is determined by the temperature of the body surface and the StefanBoltzman constant $\left(\sigma=5.6710^{-8} \mathrm{~J} / \mathrm{sm}^{2} \mathrm{~K}^{4}\right)$. As the absolute temperatures in human heat exchange do not vary much (in the order of

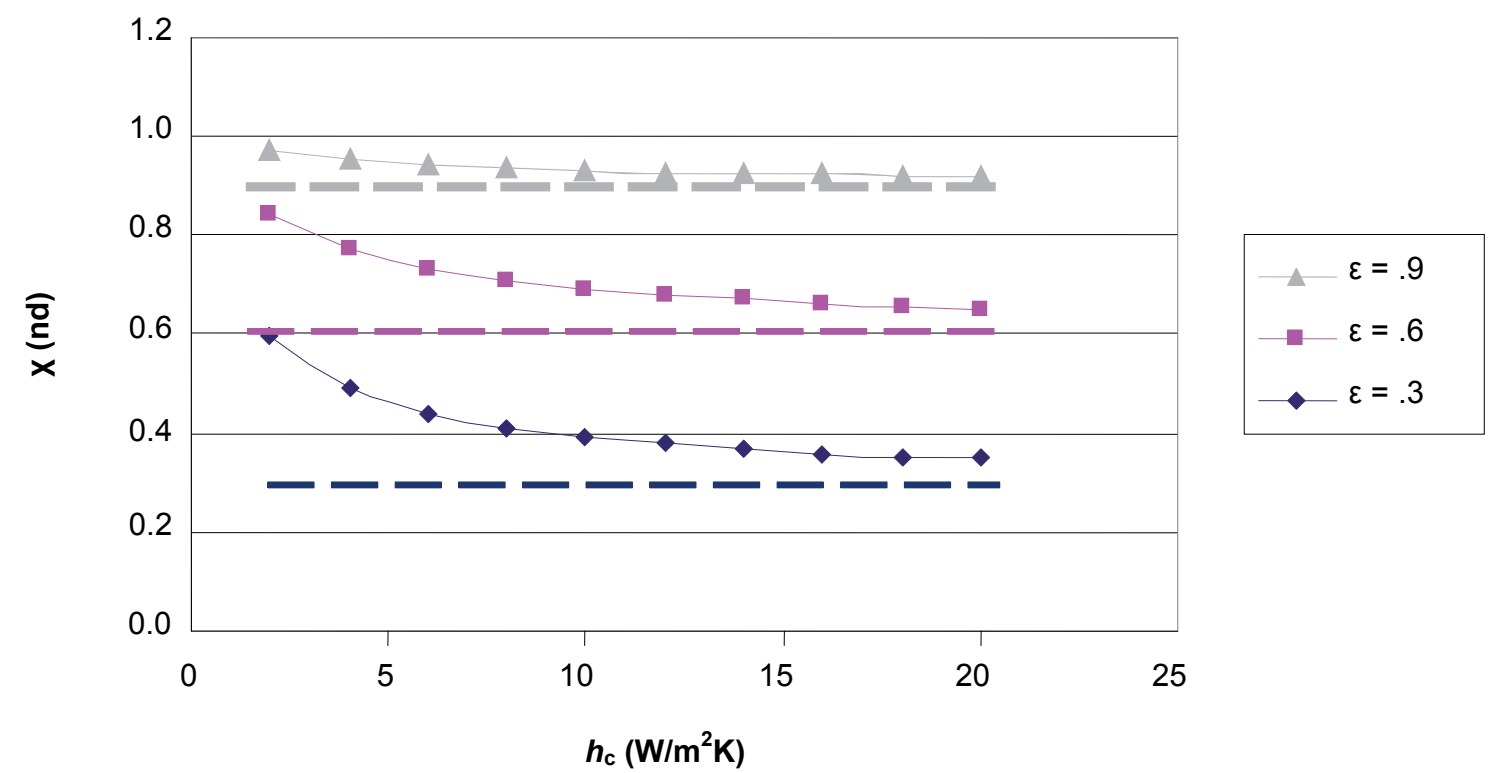

Figure 3. Dependency of $X$ on $\varepsilon$ and $h_{\mathrm{c}}$ according to Equation 9. In this graph $h_{\mathrm{r}}$ is considered constant (set at $5 \mathrm{~W} / \mathrm{m}^{2} \mathrm{~K}$ ). $\mathrm{X}$ is shown at 3 levels of $\varepsilon$ for a range of values of $h_{\mathrm{c}}$, corresponding approximately to winds of $0.5 \mathrm{~m} / \mathrm{s}\left(h_{\mathrm{c}}=5 \mathrm{~W} / \mathrm{m}^{2} \mathrm{~K}\right)$ to $5 \mathrm{~m} / \mathrm{s}\left(h_{\mathrm{c}}=20 \mathrm{~W} / \mathrm{m}^{2} \mathrm{~K}\right)$. Note that the effect of using $X$ instead of $\varepsilon$ is especially relevant for lower values of $\varepsilon$ and at lower wind speeds. The dashed lines represent the values of $\varepsilon$. Notes. $\mathrm{x}=\varepsilon\left(h_{\mathrm{r}}+h_{\mathrm{c}}\right) /\left(h_{\mathrm{c}}+\varepsilon h_{\mathrm{r}}\right)$, $\varepsilon$-emissivity (absoptivity) of a material, $h_{\mathrm{c}}$-convective heat transfer coefficient of air layer, $h_{\mathrm{r}}$-radiative heat transfer coefficient of air layer; nd-not detected. 
273-373 K) this linearization is considered valid $[2,8]$.

At this point this is a first approximation method to plot experimental data from suits with different reflectivities, in the same condition, into one graph and thus to test the model. To do this, data from the ThermProtect project were used, experimental results from manikin experiments were published before [13, 14].

This model aims to predict the change in heat exchange in a radiative field from a black globe, with which radiative environments are usually measured, to a non-black globe that accounts for the reflectivity and emissivity of the clothing in a specific radiative field. From here we convert the non-black globe into a hypothetical environment with parameters $A R T$ and a corresponding globe temperature. Still, this analysis is based on the use of a globe instead of a more human-shaped form.

\subsection{Effect of Clothing on Radiative Heat Exchange}

Proceeding from section 2.3. the clothing layer(s) have to be accounted for. Beginning with a straightforward linearized model, the heat fluxes through the clothing are

$$
h_{\mathrm{cl}}\left(T_{\mathrm{sk}}-T_{\mathrm{cl}}\right)=f_{\mathrm{cl}} h_{\mathrm{r}}\left(T_{\mathrm{cl}}-T_{\mathrm{r}}\right)+f_{\mathrm{cl}} h_{\mathrm{c}}\left(T_{\mathrm{cl}}-T_{\mathrm{a}}\right) \text {. }
$$

In Equation 11 the effect of the radiated surface being smaller than the total clothing surface area was not considered. In the analysis a homogenous radiative field was assumed. If the radiative field is not homogenous the equations have to be corrected for that via either $f_{\mathrm{cl}}$ or $T_{\mathrm{r}}$. In this equation the convective and radiative heat exchanges from the skin surface to the clothing surface have been combined and evaporative heat exchange is neglected. Take $h_{\mathrm{c}}$ and $h_{\mathrm{r}}$ together $\left(h_{\mathrm{r}}+h_{\mathrm{c}}=h_{\mathrm{air}}\right)$ and use $A R T-T_{\mathrm{a}}$ :

$$
\begin{gathered}
h_{\mathrm{cl}}\left(T_{\mathrm{sk}}-T_{\mathrm{cl}}\right) \\
=f_{\mathrm{cl}} h_{\mathrm{air}}\left(T_{\mathrm{cl}}-T_{\mathrm{a}}\right)-f_{\mathrm{cl}} h_{\mathrm{r}}\left(A R T-T_{\mathrm{a}}\right) .
\end{gathered}
$$

From this an equation for $T_{\mathrm{cl}}$ can be derived:

$$
\begin{gathered}
T_{\mathrm{cl}}=\left(h_{\mathrm{cl}} T_{\mathrm{sk}}+f_{\mathrm{cl}} h_{\mathrm{air}} T_{\mathrm{a}}\right. \\
\left.+f_{\mathrm{cl}} h_{\mathrm{r}}\left(A R T-T_{\mathrm{a}}\right)\right) /\left(h_{\mathrm{cl}}+f_{\mathrm{cl}} h_{\mathrm{air}}\right) .
\end{gathered}
$$

And as heat loss from the manikin $(M)$ can simply be stated as

$$
M=h_{\mathrm{cl}}\left(T_{\mathrm{sk}}-T_{\mathrm{cl}}\right)
$$

by filling Equation 13 into Equation 14, a straightforward equation can be made for $M$ and for the change in $M$ due to radiation $\left(M_{\text {rad }}\right.$, see Appendix for details).

$$
M_{\mathrm{rad}}=\mathrm{M}_{\mathrm{o}}-\left(A R T-T_{\mathrm{a}}\right)\left(f_{\mathrm{cl}} h_{\mathrm{r}} h_{\mathrm{cl}}\right) /\left(h_{\mathrm{cl}}+f_{\mathrm{cl}} h_{\mathrm{air}}\right) .
$$

Equation 15 basically states the attenuating effect of clothing on the impact of radiation to the manikin. If clothing insulation increases ( $h_{\mathrm{cl}}$ decreases) the change in heat loss due to radiation decreases (see Figure 4). Similarly, the effects of $f_{\mathrm{cl}}$ and convection (through $h_{\text {air }}$ ) are obtained rather straightforwardly.

For very low insulation (high $h_{\mathrm{cl}}$ ) Equation 15 states that the decrease in manikin heat loss will be linearly related to $\left(A R T-T_{\mathrm{a}}\right)$ with $f_{\mathrm{cl}} h_{\mathrm{r}}$ as the coefficient. That is basically what was stated for the situation without clothing (as $f_{\mathrm{cl}}$ will approach 1). For very high insulation (very low $h_{\mathrm{cl}}$ ) Equation 18 will transform into a constant $\left(\mathrm{M}_{\mathrm{o}}\right)$ as the loss term will become very low.

For practical reasons Equation 15 can also be written as

$$
\mathrm{M}_{\mathrm{o}}-M_{\mathrm{rad}}=K \cdot\left(A R T-T_{\mathrm{a}}\right),
$$

in which $K$ is the clothing attenuation factor of the added radiation to the manikin-clothing system.

In the testing against the experimental manikin data the decrease in manikin heat loss due to the radiation is presented and that is equal to the left term in Equation 16: $\mathrm{M}_{\mathrm{o}}-M_{\text {rad }}$. The model predicts $K \cdot\left(A R T-T_{\mathrm{a}}\right)$ to provide good estimates of the decrease in manikin heat loss due to radiation. Note that, mathematically, from Equations 10 and 16 it can be derived that $K \cdot\left(A R T-T_{\mathrm{a}}\right)$, which might also be written as $K \cdot \chi \cdot\left(T_{\mathrm{r}}-T_{\mathrm{a}}\right)$.

The data in Figure 4 show the effect of clothing insulation on the decrease in manikin heat loss due to external radiation. At low values of $h_{\mathrm{cl}}$ (thick clothing) the radiative effect on manikin heat loss tends to disappear. In practice the absolute heat loss from the manikin will be very 


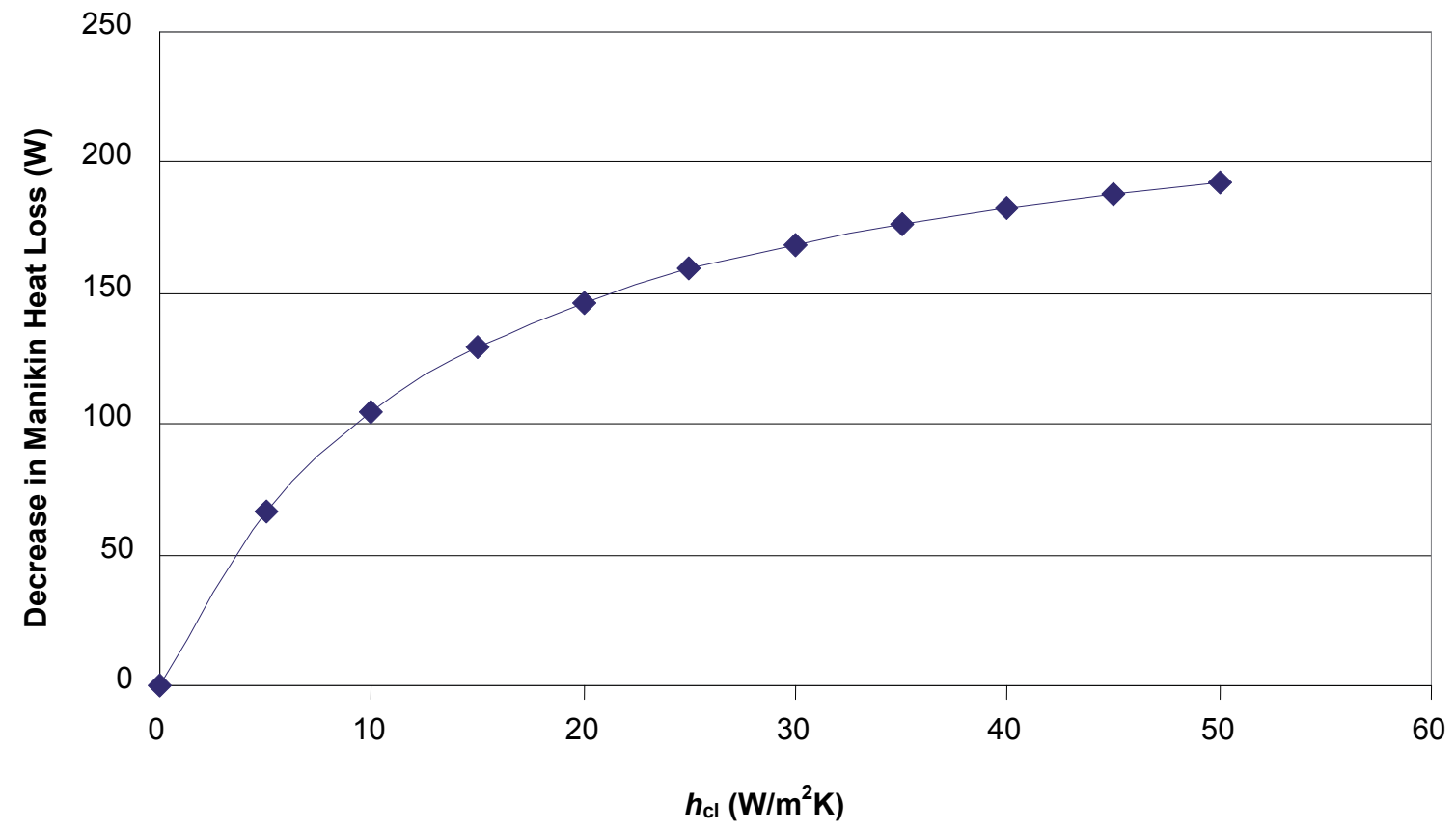

Figure 4. The effect of $h_{\mathrm{cl}}$ (clothing heat transfer, $1 / I_{\mathrm{cl}}$ ) on the decrease in manikin heat loss due to external radiation to the manikin. The shape of this curve is similar for different values of the model parameters, but absolute values will vary with apparent mean radiant temperature (ART), air temperature $\left(T_{\mathrm{a}}\right)$, radiative heat transfer coefficient of air layer $\left(h_{\mathrm{r}}\right)$, convective heat transfer coefficient of air layer $\left(h_{\mathrm{c}}\right)$ and $f_{\mathrm{cl}}$, according to Equation 15.

low at these high clothing insulation levels. At high levels of $h_{\mathrm{cl}}$ the decrease in manikin heat loss levels off. The maximum level (here at $\sim 200 \mathrm{~W}$ ) can be interpreted as the maximal effect that the radiation has on manikin heat loss, at that level the radiation will directly irradiate the manikin surface.

\subsection{The Emissivity ( $\varepsilon$ ) Model Versus the $\chi$ Model}

In the analysis that is presented in section 2.2. it is tempting to use a much simpler model, without having to introduce the concept of $A R T$.

Looking at the equations where the concept of $A R T$ is introduced

$$
\begin{gathered}
I_{\mathrm{r} \_a p p}=\varepsilon_{\text {source }} I_{\mathrm{r}}=\varepsilon_{\text {source }} h_{\mathrm{r}}\left(T_{\mathrm{r}}-T_{\mathrm{g} \_ \text {app }}\right), \\
I_{\mathrm{r} \_ \text {app }}=h_{\mathrm{r}}\left(A R T-T_{\mathrm{g} \_ \text {app }}\right) .
\end{gathered}
$$

We could go through the analysis of section 2.4. trying to implement the consequences of Equation 17 instead of the analysis of Equation 18. In Equation $17 \varepsilon_{\text {source }}$ would represent the emissivity value of the clothing to the wavelength of radiation source. That would have to lead to the introduction of $\varepsilon_{\text {source }}$ in Equations 11-16 and to a system in which Equations 15-16 become very difficult to interpret because $M_{0}$ is no longer a constant as it changes with $\varepsilon$. Without giving all details here, Equation 15 would turn into

$$
\begin{gathered}
M_{\text {rad }}=\frac{h_{\mathrm{cl}} T_{\mathrm{sk}}+f_{\mathrm{cl}}\left(h_{\mathrm{c}}+\varepsilon_{\text {source }} h_{\mathrm{r}}\right) T_{\mathrm{a}}}{\left(h_{\mathrm{cl}}+f_{\mathrm{cl}}\left(h_{\mathrm{c}}+\varepsilon_{\text {source }} h_{\mathrm{r}}\right)\right)} \\
-\frac{f_{\mathrm{cl}} \varepsilon_{\text {source }} h_{\mathrm{r}} h_{\mathrm{cl}}}{\left(h_{\mathrm{cl}}+f_{\mathrm{cl}}\left(h_{\mathrm{c}}+\varepsilon_{\text {source }} h_{\mathrm{r}}\right)\right)}\left(T_{\mathrm{r}}-T_{\mathrm{a}}\right) .
\end{gathered}
$$

The reason for this is that in not converting the environment to $A R T$ (Equation 18), Equation 17 has to be used as it incorporates the emissivity of the clothing to the source $\left(\varepsilon_{\text {source }}\right)$ explicitly. Thus, the factor $\varepsilon_{\text {source }}$ remains in all equations down to Equation 19. While analysing Equation 19 a problem seems to appear. If the radiation source was turned off, the mean radiant temperature $\left(T_{\mathrm{r}}\right)$ would become equal to air temperature $\left(T_{\mathrm{a}}\right)$. However, in Equation 19 the factor $\varepsilon_{\text {source }}$ would still be in the first term and thus affect heat exchange, even if the second source affecting the term became zero! This leads to a theoretical situation in which the emissivity of the fabric to a certain source (wavelength) has an effect on the heat exchange without the source being present. This seems incorrect and it indicates where the 
$\chi$ model, using $A R T$ is still valid as a first model approach, but where an even more simplified model, using $\varepsilon_{\text {source }}$ only, is not valid. Of course, if there is no external radiation source present, radiation is still a relevant heat loss mechanism as the clothing temperature will not be equal to the air (and mean radiant) temperature. However, in the analysis just conducted the emissivity that corresponds to the wavelengths that are emitted due to the clothing surface temperature (via Stefan-Boltzmann's law) may very well be different from the $\varepsilon_{\text {source }}$ value (as in Table 1). This will especially be the case if the external radiation source irradiates the surface at different wavelengths (visible spectrum or near IR spectrum). The wavelengths from the clothing will be in the FIR spectrum $(10-20 \mu \mathrm{m})$.

\section{RESULTS}

All measurement results were collected within the ThermProtect project. Figures 5-7 present the results, whereas Table 3 the general legend for the data and the measurement specifics.
Figure 5 is a collective chart of all available data from manikin measurements from the ThermProtect project [10]. In this figure the manikin heat gain (the decrease in manikin heat loss in the radiative condition, compared to the non-radiative condition) is plotted against the difference between mean radiant temperature and air temperature $\left(T_{\mathrm{r}}-T_{\mathrm{a}}\right)$.

The presentation of the data in Figure 5 shows that there are considerable effects, other than the radiative heat load, that affect the manikin heat loss. This is shown in Figure 5 by all the different data points with the same symbol that have varying measured heat losses ( $y$-axis values) with the same mean radiant to air temperature difference $\left(T_{\mathrm{r}}-T_{\mathrm{a}}, x\right.$-axis values). For example, the wind speed and the number of layers (total clothing insulation) are factors that influence the measured heat loss. Also, the effects of emissivity are present but not so clear in this graph.

In an attempt to better describe the collected data the model, as presented in section 2, was used to present the changes in manikin heat loss versus $\left(A R T-T_{\mathrm{a}}\right)$, i.e., the difference between apparent radiant temperature and air temperature (see Equation 9-10).

TABLE 3. Legend to Figures 4-7 Explaining the Different Experimental Conditions for the Data, Columns 2-7 Are Derived From Table 2 and Repeated Here for Clarity

\begin{tabular}{|c|c|c|c|c|c|c|c|}
\hline Symbol & $T_{\mathrm{a}}\left({ }^{\circ} \mathrm{C}\right)$ & $T_{\mathrm{r}}\left({ }^{\circ} \mathrm{C}\right)$ & $\begin{array}{l}\text { Wind } \\
(\mathrm{m} / \mathrm{s})\end{array}$ & $\begin{array}{l}\text { No. of } \\
\text { Clothing } \\
\text { Layers }\end{array}$ & $\begin{array}{c}\text { Radiation } \\
\text { Type }\end{array}$ & $\begin{array}{l}\text { Radiated } \\
\text { Area }\end{array}$ & Outer Layers \\
\hline Closed diamonds & 5 & $5 ; 41.3 ; 50$ & 0.5 & 2 & FIR & front & $\begin{array}{l}\text { Nomex@: black, orange, black } \\
\text { laminated, reflective; cotton: } \\
\text { white, black }\end{array}$ \\
\hline Closed squares & 5.9 & $6.2 ; 14.8 ; 17$ & 0.5 & 2 & VIS & front & $\begin{array}{l}\text { Nomex®: black, orange, } \\
\text { reflective; cotton: white, black }\end{array}$ \\
\hline Closed triangles & 12 & 28.8 & 0.5 & 2 & FIR & $\begin{array}{l}\text { sides }+ \\
\text { top }\end{array}$ & $\begin{array}{l}\text { Nomex@: black, orange, } \\
\text { reflective; cotton: white, black }\end{array}$ \\
\hline Open diamonds & 5.9 & $6.2 ; 14.8 ; 17$ & 1.0 & 2 & VIS & front & $\begin{array}{l}\text { Nomex®: black, orange, } \\
\text { reflective; cotton: white, black }\end{array}$ \\
\hline Crosses & 5.9 & $6.2 ; 14.8 ; 17$ & 2.0 & 2 & VIS & front & $\begin{array}{l}\text { Nomex®: black, orange, } \\
\text { reflective; cotton: white, black }\end{array}$ \\
\hline Closed circles & 5.9 & $6.2 ; 14.8 ; 17$ & 5.0 & 2 & VIS & front & $\begin{array}{l}\text { Nomex@: black, orange, } \\
\text { reflective; cotton: white, black }\end{array}$ \\
\hline Open squares & 5 & $5 ; 41.3 ; 50$ & 1.0 & 2 & FIR & front & $\begin{array}{l}\text { Nomex@: black, orange, black } \\
\text { laminated, reflective; cotton: } \\
\text { white, black }\end{array}$ \\
\hline Open triangles & 5 & $5 ; 41.3 ; 50$ & 2.0 & 2 & FIR & front & $\begin{array}{l}\text { Nomex®: black, orange, black } \\
\text { laminated, reflective; cotton: } \\
\text { white, black }\end{array}$ \\
\hline Short dashes & 5.9 & $6.2 ; 14.8 ; 17$ & 0.5 & 3 & VIS & front & Nomex $®$ : black, orange, reflective \\
\hline Open circles & 5 & $5 ; 41.3 ; 50$ & 0.5 & 3 & FIR & front & Nomex®: black, orange, reflective \\
\hline
\end{tabular}

Notes. $T_{\mathrm{a}}$-air temperature, $T_{\mathrm{r}}$ —mean radiant temperature, FIR_far infrared range, VIS—visible solar range. 


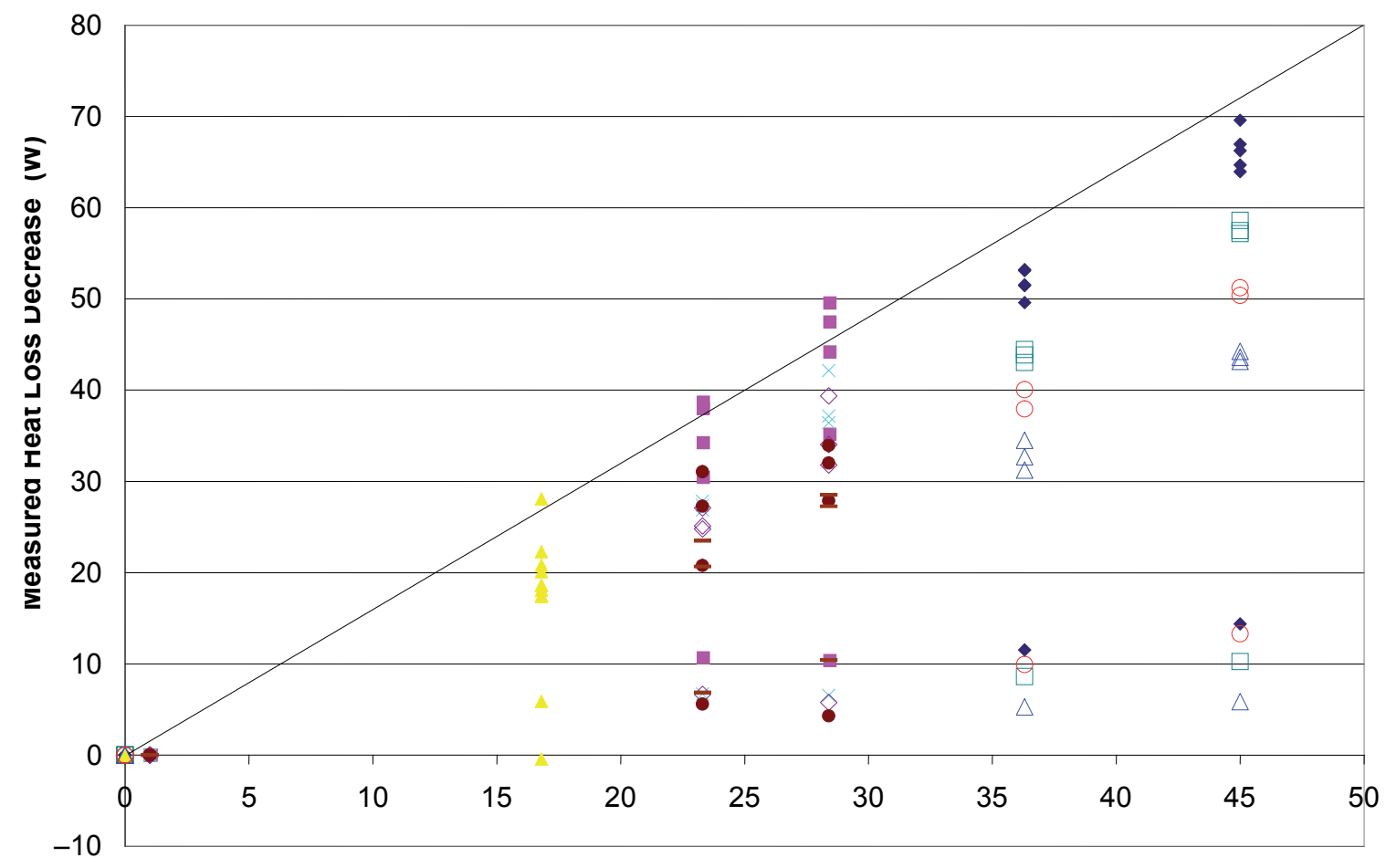

$$
\left(T_{\mathrm{r}}-T_{\mathrm{a}}\right)(\mathrm{K})
$$

Figure 5 , Collection of all available experimental data of the effect of radiation on manikin heat loss within ThermProtect. The data within each series come from the different suits that were used (see Table 3). The straight line is merely plotted as a reference to show the deviations from a single linear trend for all data. Notes. $T_{\mathrm{r}}$-mean radiant temperature, $T_{\mathrm{a}}$-air temperature.

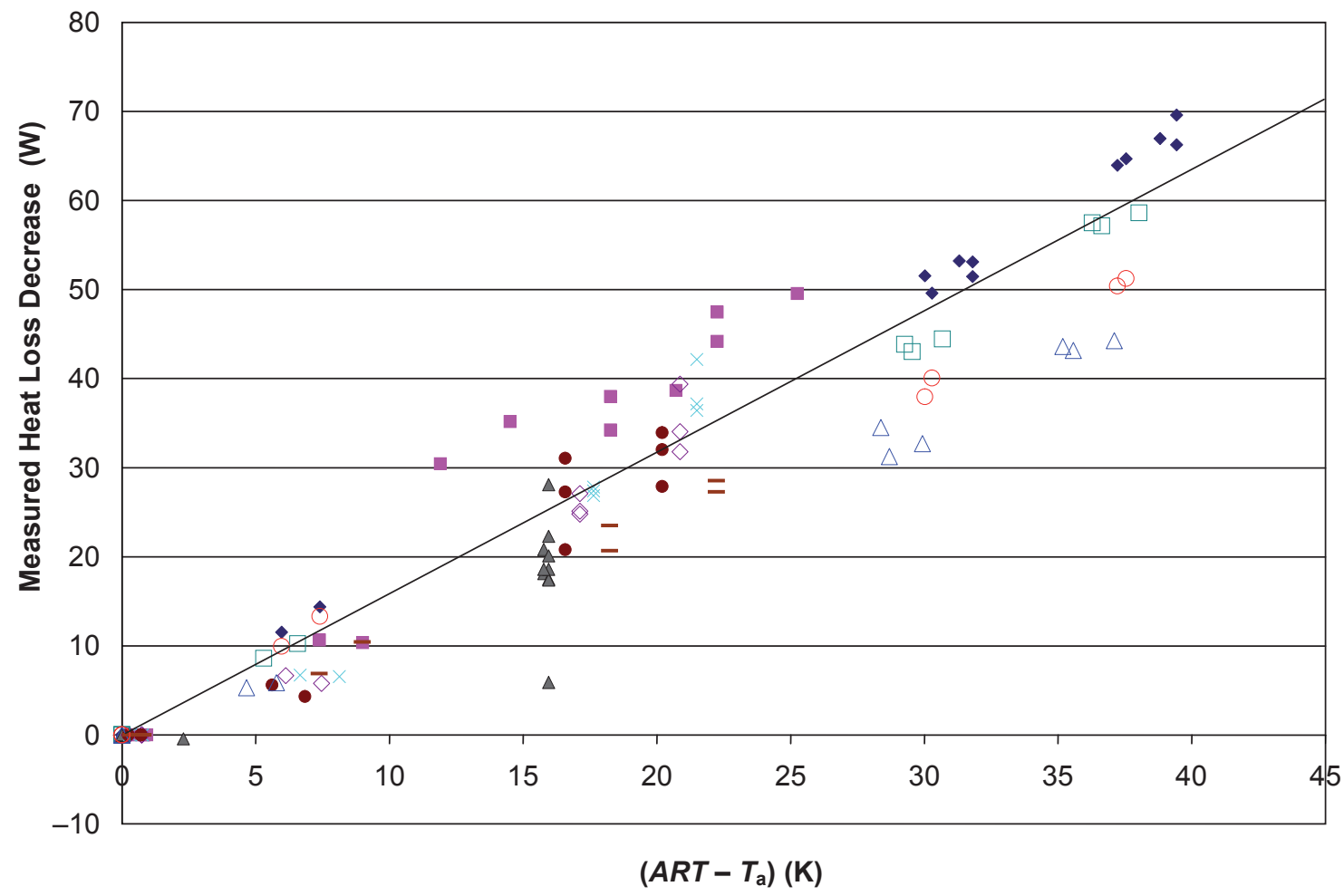

Figure 6. Experimental data on decrease in manikin heat loss plotted versus the apparent radiant and air temperature difference $\left(A R T-T_{\mathrm{a}}\right)$. Data series as in Figure 5; the straight line is merely plotted as a reference to show the deviations from a single linear trend for all data. Notes. ARTapparent mean radiant temperature, $T_{\mathrm{a}}$-air temperature. 
The values of $T_{\mathrm{r}}$ and $T_{\mathrm{a}}$ were known from the experiments, $\varepsilon$ was taken from Table 1 and the value of $h_{\mathrm{r}}$ set constant at $5 \mathrm{~W} / \mathrm{m}^{2} \mathrm{~K}$. We used two methods to determine $h_{\mathrm{c}}$ (convective heat transfer coefficient). In some datafiles the value $I_{\mathrm{a}}$, (insulation of the attached air layer) was known. In those cases we used $h_{\mathrm{c}}=1 / I_{\mathrm{a}}-h_{\mathrm{r}}$. In the other cases we used a general equation for $h_{\mathrm{c}}$ : $h_{\mathrm{c}}=8.3 \cdot \sqrt{ } v_{\text {wind }}[1,8]$.

From that, all values of $\chi$ were computed and consequently all values for $\left(A R T-T_{\mathrm{a}}\right.$ ) (Figure 6). In Figure 6 there are many fewer data points that have different measured heat loss values with the same $T_{\mathrm{r}}-T_{\mathrm{a}}$ value.

It can be seen that the data converge towards a linear model, mainly because the low heat loss decrease values, all coming from the reflective suit, have been shifted to the left. Furthermore, a clustering of the data is apparent now, caused by the fact that the use of $A R T$ does not consider differences in clothing insulation and convective heat loss (wind). Especially the clusters coming from the experimental data with three layers and from higher wind speeds are on the low side of the measured heat losses. Therefore, there is a need to account for the insulation by the clothing and the attached air layer. According to the model presented in section 2.4, the predicted heat loss equals $K \cdot \chi \cdot\left(T_{\mathrm{r}}-T_{\mathrm{a}}\right)$ and these predicted values have been plotted against the measured values in Figure 7.

The results of the model in Figure 7 show that it largely explains the effects of radiation on manikin heat loss. A linear regression through all the data pooled together yields: $y=0.970 x$ -0.621 , with $R^{2}=.953$, i.e., $95 \%$ of the variance is explained by the model. With a least squares linear estimation the standard errors of the $y$ intercept and the slope were determined to be $S E=0.525$ for the intercept and $S E=0.018$ for the slope. Thus, the regression was not significantly different from the line of identity with respect to the slope as well as the intercept. A paired $t$ test of the predicted versus measured heat loss data resulted in $p=.60$.

Only one cluster of data really falls outside the validity of the model (solid triangles). In collecting these data the left- and right-side walls and the ceiling above the manikin were the radiant sources instead of a radiation panel

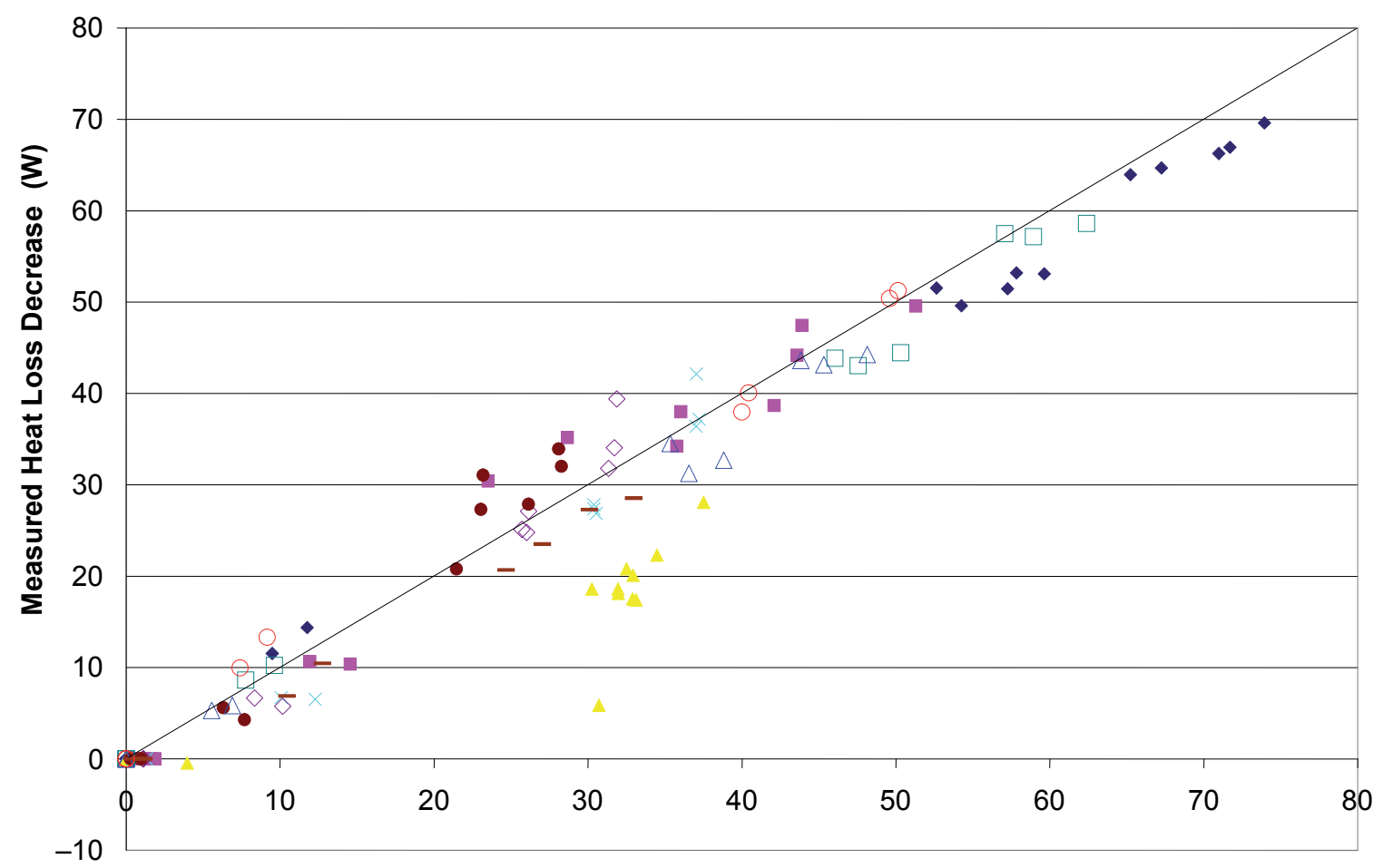

Predicted Heat Loss Decrease $\left(\mathrm{K} \bullet\left(A R T-T_{\mathrm{a}}\right)\right)(\mathrm{W})$

Figure 7. Experimental data on decrease in manikin heat loss versus the heat loss decrease predicted by the model. Data series as in Figure 5 ; the straight line represents the line of identity. Notes. ARTapparent mean radiant temperature, $T_{\mathrm{a}}$-air temperature. 
at the front or the back. The radiation from the sides and the top irradiates a smaller area of the manikin than radiation from the front; whereas, the black globe weighs all sides equally. It has not been possible to quantify the smaller size of the irradiated area of the manikin for these cases. Therefore, it was decided to keep all data in the dataset as they were. Without this data set the linear regression yielded $y=0.994 x-0.204$; $R^{2}=.982$, i.e., $98 \%$ of the variance was explained by the model.

\section{DISCUSSION}

Initially the manikin data was to be described with empirical regression modelling. It turned out to be difficult to understand the effect of radiation by making a large number of linear regressions, so an effort was made to gain a better understanding of the phenomenon. As can be seen from the material data, the value of emissivity can vary greatly, especially between solar and FIR spectra. It has to be kept in mind that the radiation from the clothing to the world will almost always be in FIR, as the surface temperature of the clothing will be in the range of 0 to $\sim 100{ }^{\circ} \mathrm{C}$ (in our experiments only to $\sim 30{ }^{\circ} \mathrm{C}$ ). These temperatures correspond to emitted radiation wavelengths of $10-20 \mu \mathrm{m}$. Thus, FIR emissivity values can be used in the basic equations and incorporated into the value for the radiative heat transfer coefficient $h_{\mathrm{r}}$. Moreover, that FIR emissivity value will largely correspond to the mean radiant temperatures we obtained during the experiment and people have become used to following Standard No. ISO 7726:2001 [17]. However, this creates a problem of other wavelengths; another emissivity value is needed especially for solar and near IR spectra. That is why this modelling effort tried to get around that by redefining the radiative environment taking the emissivity value of the actual radiative field into account. Now, we need only one emissivity value in the rest of the analysis. In the appendix a further insight into the behavior of the model is given as to how the factors $\chi$ and $K$ affect the decrease in manikin heat loss.
The experimental data seem to fit the model well. Only one cluster of data seemed to fall out of the model. In collecting these data it was noted that in these experiments the increased temperature of the side walls (left and right only) and the ceiling above the manikin were the radiant sources. The radiation from the left and right sides and the top irradiates a smaller area of the manikin than radiation from the front. As the black globe weighs all sides equally there is a shape factor that caused a difference here. The sideways and ceiling radiation affects the manikin less than radiation from the front that irradiates a larger surface area. This difference does not exist with the globe. Thus, the globe temperature and radiant temperatures, which were calculated from the globe temperature, reflect a stronger effect of the radiation coming from the sides than is actually "felt" by the manikin. Determination of the mean radiant temperatures and the apparent mean radiant temperatures should in this respect ideally have been derived from plane radiant temperatures, including the shape factors, so that it better corresponded to human surface area. This is expected to improve the results here. Methods to do that are described in Standard No. ISO 7726:2001 [17], but currently insufficient data were available to perform that analysis. In the working practice the special conditions of this specific cluster will not be realistic. Usually, conditions of higher radiation levels will exist in environments where the source will irradiate a large part of the body, because it is in the front of the body and/or the body will be moving around. Therefore, the black globe may still be a good estimate to derive the apparent mean radiant temperatures in practice.

Using all data the model quite well predicts the effect of radiation on manikin heat loss, $95 \%$ of the variation was explained by the model. The model shows a small tendency to overestimate the radiation effect, as reflected by the slope that was .97 . The data in Figure 7 suggest that especially at high values of heat loss there might be a tendency to overestimate the radiative effect. At those high temperature levels the increase in clothing and local air 
temperatures may cause additional convective heat transfer. For low and moderate levels of radiation, in the range typically addressed by the heat stress standards, the model seems to work well as is reflected by the non-significant difference between the measured and predicted data sets $(p=.60)$. At high radiation levels this model has not been validated yet. The system as determined by Equations 10 and 16 seems highly linear, but this is partly caused by the oversimplification of using $h_{\mathrm{r}}$ as a standard value. At a higher radiation level this approach may not be valid any more and the effect of increasing $h_{\mathrm{r}}$ should be taken into account $[2,7]$. In the manikin experiments that have been used to validate the model [10], radiation levels were largely within the linearity of this approach. As a constant value of the radiative heat transfer coefficient $h_{\mathrm{r}}$ was used, the model is now really limited to low and medium ranges of radiation. The precise range of validity needs to be studied further and will depend on clothing, air and mean radiant temperatures. If the clothing surface temperatures from the manikin experiments are available, an actual effective value of $h_{\mathrm{r}}$ could computed to correct for the increasing radiative heat exchange with increasing clothing temperatures at higher radiation levels. It is also expected that extra convective heat transfer will become very important. This means that this model is not yet useful for the analysis for high radiant heat conditions, such as firefighters and blast furnaces. However, this paper shows some directions for further research.

\subsection{Transmission}

The transmission of radiation through clothing has not been taken into account yet. Lotens [8] described a model in which it could be incorporated into this model. As the present effort was a first order initial approach, the transmission was not taken into account separately, but taken as a part of the absorbed radiation. Any radiation that is transmitted through the outer layer will be absorbed by the underclothing or the skin, unless a strong reflective layer is worn as the under layer. The difference is that the radiation is absorbed closer to the skin, which would in practice lead to a higher heat load to the wearer, cf. Equations 15-16. This is due to the fact that the point where that part of the radiation is absorbed "sees" a lower clothing insulation $\left(I_{\mathrm{cl}}\right.$ or higher $\left.h_{\mathrm{cl}}\right)$. In the model, this leads to a higher effect of radiation on the manikin heat loss, and thus a higher heat load to the wearer. In future extensions of this model, transmission could be incorporated, which for very light weight normal clothing transmission may be a factor. For protective clothing, the transmission will usually be low as seen in Table 1 .

\subsection{Limitations and Conclusions}

This model is a first approximation to understand the radiative effects that were found in the experimental studies. It has its limitations in validity due to simplifications used to linearize the process. Partly, this could be improved by taking actual clothing temperatures into account, which will become available from the experiments. On the other hand, the approach using ART has its limitations: it is a hypothetical model that accounts the different emissivity values that should be used. Still, the model shows that the results from the manikin experiments can be used in one approach. However, to perform a completely correct and valid analysis, more input would be required, limiting its use for practice and in standards. Therefore, this model, aiming at finding an optimum between basic physics and practical use, may have useful meaning in practice, while still providing some basic physics background. The model predictions may be further improved by incorporating the effects of transmission of radiation through the outer clothing layer and by correcting the radiative heat transfer coefficient for actual temperatures in the outer clothing layer.

\section{REFERENCES}

1. Kerslake DMcK. The stress of hot environments. Cambridge, UK: Cambridge University Press; 1972.

2. Malchaire J, Piette A, Kampmann B, Mehnert P, Gebhardt H, Havenith G, et al. Development and validation of the predicted heat strain model. Ann Occup Hyg. 2001;45(2):123-35. 
3. Barker RL, Guerth-Schacher C, Grimes RV, Hamouda. H. Effects of moisture on the thermal protective performance of firefighter protective clothing in low-level radiant heat exposures. Text Res J. 2006; 76(1):27-31.

4. Keiser C, Rossi RM. Temperature analysis for the prediction of steam formation and transfer in multilayer thermal protective clothing at low level thermal radiation. Text Res J. 2008; 78(11):1025-35.

5. Qian X, Fan J. A quasi-physical model for predicting the thermal insulation and moisture vapour resistance of clothing. Appl Ergon. 2009;40:577-90.

6. Talukdar P, Torvi DA, Simonson CJ, Sawcyn CMJ. Coupled CFD and radiation simulation of air gaps in bench top protective fabric tests. Int $\mathrm{J}$ Heat Mass Transf. 2010;53:526-39.

7. International Organization for Standardization (ISO). Ergonomics of the thermal environment-analytical determination and interpretation of heat stress using calculation of the predicted heat strain (Standard No. ISO 7933:2004). Geneva, Switzerland: ISO; 2004.

8. Lotens WA. Heat transfer from humans wearing clothing [doctoral dissertation]. Delft, The Netherlands: Delft University of Technology; 1993.

9. Havenith G. Individual heat stress response [doctoral dissertation]. Nijmegen, The Netherlands: Catholic University Nijmegen; 1997.

10. Havenith G, Holmér I, Meinander H, den Hartog EA, Richards M, Bröde P, et al. Assessment of thermal properties of protective clothing and their use. Final technical report THERMOPROTECT, European Union Contract No. G6RDCT-2002-00846; 2006.

11. Havenith G, Wang X, THERMPROTECT network. Interaction effects of radiation and convection measured by a thermal manikin wearing protective clothing with different radiant properties. In: 3rd International Conference on HumanEnvironment Systems; 2005. p. 47-50.

12. Bröde $P$, Kuklane, K, den Hartog EA, Havenith G. Infrared radiation effects on heat loss measured by a thermal manikin wearing protective clothing. In:
Environmental Ergonomics XI, Proceedings of the 11th International Conference; 2005. p. 74-9.

13. Bröde $\mathrm{P}$, Candas V, Kuklane $\mathrm{K}$, den Hartog EA, Havenith G. Effects of heat radiation on the heat exchange with protective clothing-a thermal manikin study. In: 3rd European Conference on Protective Clothing (ECPC) and NOKOBETEF 8. Protective Clothing Towards Balanced Protection [CD-ROM). Warszawa, Poland: Central Institute for Labour Protection - National Research Institute; 2006.

14. Kuklane K, Gao C, Holmér I, Broede P, Candas V, den Hartog E, Havenith G, et al. Effects of natural solar radiation on manikin heat exchange. In: 3rd European Conference on Protective Clothing (ECPC) and NOKOBETEF 8. Protective Clothing Towards Balanced Protection [CD-ROM). Warszawa, Poland: Central Institute for Labour Protection - National Research Institute; 2006.

15. Fukazawa T, den Hartog EA, Daanen HAM, Penders-van-Elk N, Tochihara Y, Havenith G. Radiant heat transfer network in the simulated protective clothing system under high heat flux. In: The Third International Conference on Human-Environment System ICHES '05; 2005. p. 435-8.

16. European Committee for Standardization (CEN). Glass in building-determination of luminous and solar characteristics of glazing (Standard No. EN 410:1998). Brussels, Belgium: CEN; 1998.

17. Internal Organization for Standardization (ISO). Ergonomics of the thermal environment-instruments for measuring physical quantities (Standard No. ISO 7726:2001). Geneva, Switzerland; ISO: 2001.

18. van Es EM, den Hartog EA, Broede P, Candas V, Heus R, Havenith $G$, et al. Effects of short wave radiation and radiation area on human heat strain in reflective and non-reflective protective clothing. In: 3rd European Conference on Protective Clothing (ECPC) and NOKOBETEF 8. Protective Clothing Towards Balanced Protection [CD-ROM]. Warszawa, Poland: Central Institute for Labour Protection - National Research Institute; 2006. 


\section{APPENDIX}

Extra steps in derivation of the clothing attenuation effect on radiative heat exchange:

$$
h_{\mathrm{cl}} \cdot\left(T_{\mathrm{sk}}-T_{\mathrm{cl}}\right)=f_{\mathrm{cl}} \cdot \mathrm{h}_{\mathrm{c}} \cdot\left(T_{\mathrm{cl}}-T_{\mathrm{a}}\right)+\mathrm{f}_{\mathrm{cl}} \cdot h_{\mathrm{r}} \cdot\left(T_{\mathrm{cl}}-A R T\right) .
$$

Here there is only a formal separation between radiative and convective part of $h_{\mathrm{cl}}$, taken together as

$$
\begin{aligned}
& h_{\mathrm{cl}}=h_{\mathrm{cl}, \mathrm{c}}+h_{\mathrm{cl}, \mathrm{r}} \\
& h_{\mathrm{cl}} \cdot\left(T_{\mathrm{sk}}-T_{\mathrm{cl}}\right)=f_{\mathrm{cl}} \cdot h_{\mathrm{c}} \cdot\left(T_{\mathrm{cl}}-T_{\mathrm{a}}\right)+f_{\mathrm{cl}} \cdot h_{\mathrm{r}} \cdot\left(T_{\mathrm{cl}}-\left[A R T-T_{\mathrm{a}}+T_{\mathrm{a}}\right]\right) .
\end{aligned}
$$

It is useful to rename $A R T-T_{\mathrm{a}}$ to $d T_{\mathrm{ra}}$ :

$$
h_{\mathrm{cl}} \cdot\left(T_{\mathrm{sk}}-T_{\mathrm{cl}}\right)=f_{\mathrm{cl}} \cdot h_{\mathrm{c}} \cdot\left(T_{\mathrm{cl}}-T_{\mathrm{a}}\right)+f_{\mathrm{cl}} \cdot h_{\mathrm{r}} \cdot\left(T_{\mathrm{cl}}-T_{\mathrm{a}}\right)-f_{\mathrm{cl}} \cdot h_{\mathrm{r}} \cdot d T_{\mathrm{ra}} \cdot
$$

The basics of this is $k A=k A-k B+k B=k B+k(A-B)$ :

$$
h_{\mathrm{cl}} \cdot\left(T_{\mathrm{sk}}-T_{\mathrm{cl}}\right)=f_{\mathrm{cl}} \cdot\left(h_{\mathrm{c}}+h_{\mathrm{r}}\right) \cdot\left(T_{\mathrm{cl}}-T_{\mathrm{a}}\right)-f_{\mathrm{cl}} \cdot h_{\mathrm{r}} \cdot d T_{\mathrm{ra}} .
$$

If desired, $h_{\mathrm{c}}+h_{\mathrm{r}}$ can be combined into $h_{\text {air }}$ :

$$
\begin{aligned}
& h_{\mathrm{cl}} \cdot\left(T_{\mathrm{sk}}-T_{\mathrm{cl}}\right)=f_{\mathrm{cl}} \cdot h_{\mathrm{air}} \cdot\left(T_{\mathrm{cl}}-T_{\mathrm{a}}\right)-f_{\mathrm{cl}} \cdot h_{\mathrm{r}} \cdot d T_{\mathrm{ra}}, \\
& \left(h_{\mathrm{cl}}+f_{\mathrm{cl}} \cdot h_{\mathrm{air}}\right) \cdot T_{\mathrm{cl}}=h_{\mathrm{cl}} \cdot T_{\mathrm{sk}}+f_{\mathrm{cl}} \cdot h_{\mathrm{air}} \cdot T_{\mathrm{a}}+f_{\mathrm{cl}} \cdot h_{\mathrm{r}} \cdot d T_{\mathrm{ra}}, \\
& T_{\mathrm{cl}}=\left(h_{\mathrm{cl}} \cdot T_{\mathrm{sk}}+f_{\mathrm{cl}} \cdot h_{\mathrm{air}} \cdot T_{\mathrm{a}}+f_{\mathrm{cl}} \cdot h_{\mathrm{r}} \cdot d T_{\mathrm{ra}}\right) /\left(h_{\mathrm{cl}}+f_{\mathrm{cl}} \cdot h_{\mathrm{air}}\right) .
\end{aligned}
$$

Initially, we stated that the heat loss from the manikin $(M)$ equals

$$
M=h_{\mathrm{cl}} \cdot\left(T_{\mathrm{sk}}-T_{\mathrm{cl}}\right) .
$$

Equations $\mathrm{A} 0$ and $\mathrm{A} 7$ combined give

$$
\begin{aligned}
& M=h_{\mathrm{cl}} \cdot T_{\mathrm{sk}}-h_{\mathrm{cl}} \cdot T_{\mathrm{cl}}, \\
& M=h_{\mathrm{cl}} \cdot T_{\mathrm{sk}}-h_{\mathrm{cl}} \cdot\left(\left(h_{\mathrm{cl}} \cdot T_{\mathrm{sk}}+f_{\mathrm{cl}} \cdot h_{\mathrm{air}} \cdot T_{\mathrm{a}}+f_{\mathrm{cl}} \cdot h_{\mathrm{r}} \cdot d T_{\mathrm{ra}}\right) /\left(h_{\mathrm{cl}}+f_{\mathrm{cl}} \cdot h_{\mathrm{air}}\right)\right) .
\end{aligned}
$$

In the first term on the right the radiation does not explicitly appear, and if $A R T=T_{\mathrm{a}}$ and/or $T_{\mathrm{r}}=T_{\mathrm{a}}$ the term with $d T_{\mathrm{ra}}$ becomes zero. Thus, the right-hand side terms can be separated into a radiative effect and a non-radiative effect. For limitations to this approach see the text.

$$
\begin{aligned}
& M=h_{\mathrm{cl}} \cdot T_{\mathrm{sk}}-h_{\mathrm{cl}} \cdot\left(\left(h_{\mathrm{cl}} \cdot T_{\mathrm{sk}}+f_{\mathrm{cl}} \cdot h_{\mathrm{air}} \cdot T_{\mathrm{a}}\right) /\left(h_{\mathrm{cl}}+f_{\mathrm{cl}} \cdot h_{\mathrm{air}}\right)\right) \\
& -d T_{\mathrm{ra}} \cdot\left(h_{\mathrm{cl}} \cdot f_{\mathrm{cl}} \cdot h_{\mathrm{r}}\right) /\left(h_{\mathrm{cl}}+f_{\mathrm{cl}} \cdot h_{\mathrm{air}}\right) \\
& M=\mathrm{M}_{\mathrm{o}}-d T_{\mathrm{ra}} \cdot\left(h_{\mathrm{cl}} \cdot f_{\mathrm{cl}} \cdot h_{\mathrm{r}}\right) /\left(h_{\mathrm{cl}}+f_{\mathrm{cl}} \cdot h_{\mathrm{air}}\right)
\end{aligned}
$$

This equals Equation 15 (on p. 253) as $d T_{\mathrm{ra}}=A R T-T_{\mathrm{a}}$. 
